\title{
Structural properties and gelatinisation characteristics of potato and cassava starches and mutants thereof
}

\author{
S.V. Gomand ${ }^{\mathrm{a}, *}$, L. Lamberts ${ }^{\mathrm{a}}$, L.J. Derde ${ }^{\mathrm{a}}$, H. Goesaert ${ }^{\mathrm{a}}$, G.E. Vandeputte ${ }^{\mathrm{a}}$, B. Goderis ${ }^{\mathrm{b}}$, R.G.F. Visser ${ }^{\mathrm{c}}$, \\ J.A. Delcour ${ }^{\mathrm{a}}$ \\ ${ }^{a}$ Laboratory of Food Chemistry and Biochemistry, and Leuven Food Science and Nutrition Research Centre (LFoRCe), Katholieke Universiteit Leuven, \\ Kasteelpark Arenberg 20, B-3001 Leuven, Belgium \\ ${ }^{\mathrm{b}}$ Molecular and Nanomaterials, Chemistry Department, Katholieke Universiteit Leuven, Celestijnenlaan 200F, B-3001 Leuven, Belgium \\ ${ }^{c}$ Laboratory of Plant Breeding, Department of Plant Sciences, Wageningen University and Research Centre, PO Box 386, NL-6700 AJ Wageningen, The Netherlands
}

\section{A R T I C L E I N F O}

\section{Article history:}

Received 26 August 2009

Accepted 12 October 2009

\section{Keywords:}

Potato starch

Cassava starch

Molecular size

Chain length distribution

Crystallinity

Gelatinisation

\begin{abstract}
A B S T R A C T
The molecular size of amylopectin (AP) and amylose (AM), AP chain length distribution, crystallinity and granular structure (morphology and granule size distribution) of five wild type potato starches (wtps), five AM free potato starches (amfps), four high-AM potato starches (haps), one wild type cassava starch (wtcs) and one AM free cassava starch (amfcs) were investigated and related to their gelatinisation characteristics. Starches with higher levels of short chains [degree of polymerisation (DP) 6-9 and DP 1014)] had lower gelatinisation onset $\left(T_{\mathrm{o}}\right)$, peak $\left(T_{\mathrm{p}}\right)$ and conclusion $\left(T_{\mathrm{c}}\right)$ temperatures, whereas higher contents of longer chains (DP 18-25 and DP 25-80) led to higher gelatinisation temperatures. Gelatinisation enthalpies $(\Delta H)$ increased with degree of crystallinity. The granules of wtps were larger than those of amfps and haps, respectively. No differences in morphology were observed between wtps and amfps granules, but the haps granules had more irregular surfaces and showed multi-lobed granules.
\end{abstract}

(c) 2009 Elsevier Ltd. All rights reserved.

\section{Introduction}

Starch is the main constituent of many roots and tubers. Its variety of structures and, consequently, physicochemical properties, offers numerous possibilities for industrial applications. There is a continuous demand for novel starch properties. It is hence very important to understand the link between structural aspects and physicochemical properties (Fredriksson, Silverio, Andersson, Eliasson, \& Aman, 1998; Jobling, 2004; Vandeputte, Derycke, Geeroms,

\footnotetext{
Abbreviations: AP, amylopectin; AM, amylose; amfcs, amylose free cassava starch; amfps, amylose free potato starches; CL, chain length; conA, concanavalinA; DSC, differential scanning calorimetry; dm, dry matter; DP, degree of polymerisation; $\Delta H$, enthalpy; GOPOD, glucose oxidase/peroxidase; glc-6-P, glucose-6-phosphate; GBSS, granule bound starch synthase; haps, high-amylose potato starches; HPAEC, high performance anion-exchange chromatography; HPSEC, high performance size exclusion chromatography; MW, molecular weight; $\mathrm{NAD}^{+}$, nicotineamide adenosine dinucleotide; R, Pearson correlation coefficient; PAD, pulsed amperometric detection; RC, relative crystallinity; RNA, ribonucleic acid; SEM, scanning electron microscopy; SEC, size exclusion chromatography; SBE, starch branching enzymes; SS, starch synthases; $T_{0}$, onset temperature; $T_{\mathrm{p}}$, peak temperature; $T_{\mathrm{c}}$, conclusion temperature; wtcs, wild type cassava starch; wtps, wild type potato starches.

* Corresponding author. Tel.: +32 16 321582; fax: +32 16321997.

E-mail address: sara.gomand@biw.kuleuven.be (S.V. Gomand).
}

\& Delcour, 2003; Vandeputte, Vermeylen, Geeroms, \& Delcour, 2003a, 2003b).

Common granular starch is semi-crystalline. It consists of amylopectin [AP, a highly branched $\alpha$-(1,4)-glucan with $5 \% \alpha$ - $(1,6)-$ bonds, MW $=1.7 \times 10^{8}$ for wild type potato starch (wtps), $2.0 \times 10^{8}$ for amylose free potato starch (amfps), $0.7 \times 10^{8}$ for wild type cassava starch (wtcs)] (Yoo \& Jane, 2002) and amylose [AM, a nearly linear $\alpha$-(1,4)-glucan, molecular weight $(\mathrm{MW})=1.03 \times 10^{6}$ for wtps, $1.08 \times 10^{6}$ for wtcs] (Morrison \& Karkalas, 1990).

In the generally accepted AP structural model, the short AP chains form double helices which are organised in clusters. These clusters are connected by the long chains of AP which extend in two or more clusters (Fig. 1). The chain length (CL, i.e. the number of glucose residues making up one chain) distribution is polymodal (Hizukuri, 1986). A chains (outer chains) are attached to B chains. The latter are linked to other $B$ chains or the $C$ chain and carry one or more A chains. The $C$ chain contains the single reducing group of AP. B1 chains are located in 1 cluster while B2, B3 and B4 chains span 2, 3 and 4 clusters, respectively (Hizukuri, 1986). Potato starch is unique in that it contains phosphate ester groups $(0.2-0.4 \%$ of the glucose units) (Takeda \& Hizukuri, 1982), covalently linked to AP mainly at the C-6 (61\%) and C-3 (38\%) positions with small levels on the C-2 position (Tabata \& Hizukuri, 1971). 


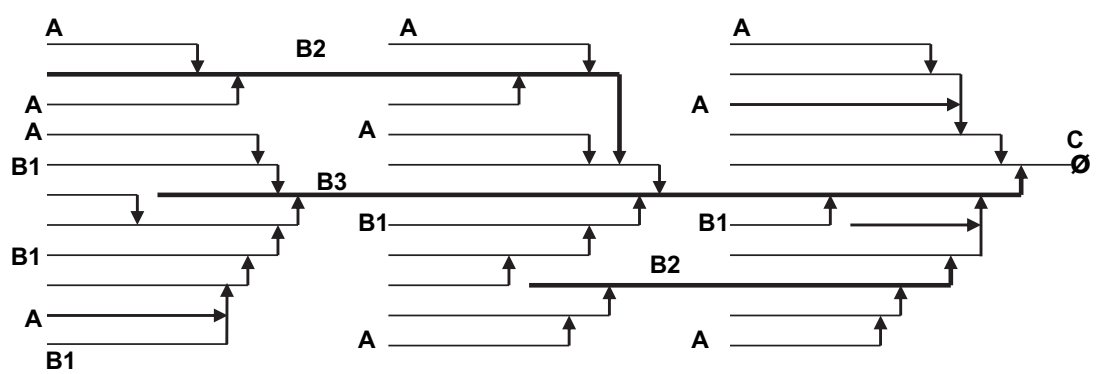

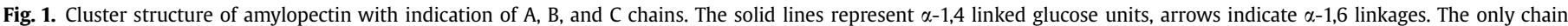

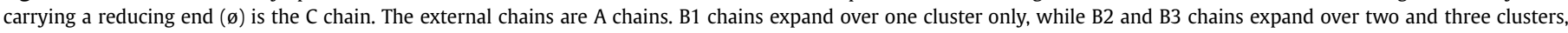
respectively. Adapted from Hizukuri (1986).

Starch itself has different levels of organisation [from granules (2-100 $\mu \mathrm{m})$ (Buléon, Colonna, Planchot, \& Ball, 1998) to growth rings (120-500 nm) (French, 1984), blocklets (20-500 nm) (Gallant, Bouchet, \& Baldwin, 1997), lamellae (9-10 nm) (Jenkins, Cameron, \& Donald, 1993) and AP and AM molecules (0.1-1.0 nm)]. Granules consist of alternating semi-crystalline and amorphous growth rings. AM is deposited mainly in the amorphous growth rings and, to a small extent, in the semi-crystalline growth rings (Jenkins \& Donald, 1995). In contrast, semi-crystalline growth rings are built from alternating amorphous and crystalline lamellae of the AP structure. Irrespective of the botanical origin, the repeat distance of the combination of one amorphous and one crystalline lamella is $9 \mathrm{~nm}$ (Oostergetel \& van Bruggen, 1989). It has been suggested that the lamellae of AP behave like side-chain liquid-crystalline polymers. In this view, the double helices form the rigid units, while the spacer units contain the branch points of AP and possibly AM (Daniels \& Donald, 2003). The spacer units are connected to the long, flexible backbones of AP (Waigh et al., 2000, Donald, Kato, Perry, \& Weigh, 2001).

The structure of starch results from the action of different biosynthetic enzymes. Impacting biosynthetic pathways yields starches with different AM/AP ratios. Granule bound starch synthase (GBSS) primarily catalyses AM synthesis (Kuipers, Jacobsen, \& Visser, 1994). In the case of potato starch, antisense ribonucleic acid (RNA) inhibition of the expression of GBSS (Visser et al., 1991) or mutation by Röntgen-irradiation (Hovenkamp-Hermelink et al., 1987) have led to amfps. Both CL distribution of short chains [degree of polymerisation (DP) $<35$, as measured by HPAECl and granule morphology are comparable for wtps and amfps (Visser, Suurs, Bruinenberg, Bleeker, \& Jacobsen, 1997, Fulton et al., 2002). The starch branching enzymes (SBE) A and B catalyse the hydrolysis of an $\alpha-(1,4)$-bond followed by transfer of the liberated reducing end for the formation of an $\alpha-(1,6)-$ bond. Repression of SBE A and SBE B activities results in an up to sixfold increased degree of phosphorylation (Schwall et al., 2000) and AM contents up to $89 \%$, depending on the used determination method. It drastically changes the AP structure [an increase in longer chains of DP $>20$ ] and the resultant granules show deep fissures and irregular surfaces (Schwall et al., 2000, Blennow et al., 2005).

The current study aimed to explore the relation between the structure of potato and cassava starches and their gelatinisation behaviour. To that end, five wtps, five amfps, four high-AM potato starches (haps), one wtcs and one amylose free cassava starch (amfcs) were studied. As these genetically modified starches have only been characterised to a limited degree, an extensive study of the structure and the physicochemical properties of these starches is necessary. In the present study, molecular (crystallinity, molecular size distribution, CL distribution) and granular (morphology and size distribution) structure of these starches was analysed. In addition, we here for the first time report on the impact of these properties on gelatinisation characteristics.

\section{Materials and methods}

\subsection{Materials}

Table 1 lists all potato and cassava starches, their genotype and the corresponding enzyme suppression. They were obtained from Wageningen University (Wageningen, The Netherlands) or BASF Plant Science Holding GmbH (Ludwigshafen, Germany). Sixteen starches were investigated: five wild type potato starches (wtps1wtps5), five AM free potato starches (amfps1-amfps5), four highAM potato starches (haps1-haps4), one wild type cassava starch (wtcs) and one AM free cassava starch (amfcs). Sample numbers wtps 3 and amfps 3 originate from a mix of different genotypes. All amfps and amfcs samples were the result of (partial) RNA inhibition of GBSS, except for amfps3 which resulted from point mutation of GBSS by X-ray irradiation. haps samples were the result of (partial) RNA inhibition of SBE A and SBE B.

All reagents, chemicals and enzymes used were of at least analytical grade and obtained from Sigma-Aldrich (Bornem, Belgium) unless indicated otherwise. Where enzymes were used, their Units (U) were as defined by the respective suppliers.

\section{Table 1}

Overview of the examined starches with their corresponding genotype and the corresponding suppressed enzymes.

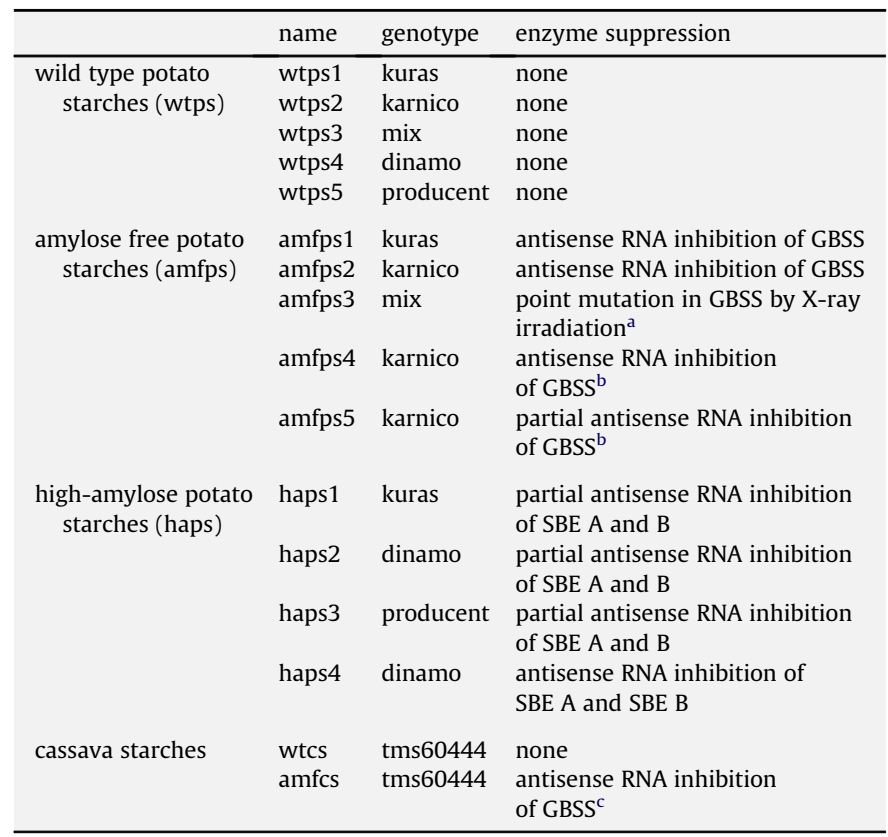

\footnotetext{
a Visser et al. (1997).

b Kuipers et al. (1994).

c Raemakers et al. (2005).
} 
Table 2

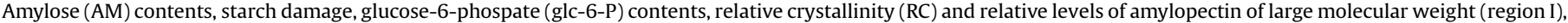

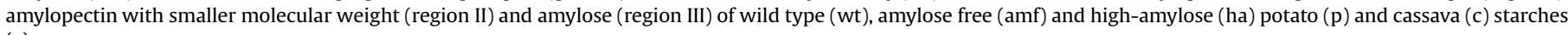
(s).

\begin{tabular}{|c|c|c|c|c|c|c|c|}
\hline sample & AM content (\%) & starch damage (\%) & glc-6-Pcontent (nmol/mg) & $\mathrm{RC}(\%)$ & region I (\%) & region II (\%) & region III (\%) \\
\hline wtps1 & $18.9(0.6)$ & $0.8(0.1)$ & $16.9(0.8)^{\mathrm{f}}$ & 30.0 & $42.1(1.2)$ & $33.4(0.0)$ & $24.5(1.3)$ \\
\hline wtps2 & $22.4(0.3)$ & $0.7(0.0)$ & $9.2(0.8)^{i, j}$ & 30.0 & $41.1(3.1)$ & $28.7(2.7)$ & $30.2(0.8)$ \\
\hline wtps3 & $20.3(0.2)$ & $0.2(0.0)$ & $9.8(0.5)^{\mathrm{j}}$ & 33.0 & $48.6(2.4)$ & $25.8(0.8)$ & $25.5(3.3)$ \\
\hline wtps4 & $20.7(0.3)$ & $0.7(0.0)$ & $20.4(0.6)^{\mathrm{e}}$ & 36.0 & $46.1(2.5)$ & $24.7(1.5)$ & $29.2(1.1)$ \\
\hline wtps5 & $19.9(0.9)$ & $0.9(0.0)$ & $12.8(1.1)^{\mathrm{h}, \mathrm{g}}$ & 35.5 & $40.4(1.1)$ & $30.3(2.5)$ & $29.3(1.6)$ \\
\hline amfps1 & $3.9(0.1)$ & $0.8(0.1)$ & $21.4(1.1)^{\mathrm{e}}$ & 36.0 & $50.2(3.5)$ & $37.0(3.4)$ & $12.9(1.5)$ \\
\hline amfps2 & $3.6(0.0)$ & $0.7(0.0)$ & $10.6(1.0)^{h, i, j}$ & 37.5 & $42.4(1.8)$ & $41.4(0.8)$ & $16.2(1.0)$ \\
\hline amfps3 & $4.2(0.2)$ & $0.3(0.0)$ & $8.6(0.6)^{\mathrm{j}}$ & 38.5 & $22.2(0.5)$ & $50.5(2.4)$ & $27.3(1.9)$ \\
\hline amfps4 & $7.5(0.2)$ & $0.8(0.0)$ & $14.4(1.0)^{\mathrm{f}, \mathrm{g}}$ & 34.0 & 58.7 (1.9) & $31.6(1.2)$ & $9.7(1.7)$ \\
\hline amfps5 & $3.9(0.1)$ & $0.8(0.0)$ & $11.6(0.8)^{\mathrm{h}, \mathrm{i}}$ & 34.0 & $57.5(1.2)$ & $29.2(1.1)$ & $13.4(0.9)$ \\
\hline haps1 & $27.4(0.5)$ & $0.8(0.0)$ & $64.3(2.6)^{c}$ & 28.5 & $30.2(2.9)$ & $31.1(2.1)$ & $39.0(1.6)$ \\
\hline haps2 & 33.1 (1.6) & $0.8(0.0)$ & $73.3(1.2)^{\mathrm{a}}$ & 29.0 & $10.2(1.5)$ & $30.3(4.3)$ & $59.5(5.7)$ \\
\hline haps3 & $37.3(1.3)$ & $0.9(0.0)$ & $69.5(0.8)^{b}$ & 26.5 & $18.7(1.4)$ & $29.2(0.5)$ & $52.1(1.4)$ \\
\hline haps 4 & $78.4(0.9)$ & $0.3(0.0)$ & $50.0(1.8)^{\mathrm{d}}$ & 21.0 & $1.6(0.2)$ & $10.8(0.6)$ & $87.6(0.8)$ \\
\hline wtcs & $18.4(0.1)$ & $1.3(0.0)$ & $0.0(0.0)^{\mathrm{k}}$ & 40.0 & $43.8(1.5)$ & $28.7(1.3)$ & $27.6(1.7)$ \\
\hline amfcs & $6.0(0.1)$ & $1.2(0.0)$ & $0.0(0.0)^{\mathrm{k}}$ & 49.0 & $52.9(2.1)$ & $33.3(0.9)$ & $13.8(1.6)$ \\
\hline
\end{tabular}

Results indicated with the same letter are not significantly different $(P<0.05)$.

\subsection{AM content}

AM and starch contents were determined according to a Megazyme (Bray, Ireland) procedure, which itself is based on the method developed by Yun and Matheson (1990). For the AM content determination, samples were incubated with concanavalinA (conA) to precipitate AP. Next, AM, which remained in the supernatant, was measured. AM content and starch content were determined after degradation with a mixture of amyloglucosidase $/ \alpha$-amylase and incubation with glucose oxidase/peroxidase (GOPOD, Megazyme). Analyses were performed in triplicate and AM content was expressed as \% of total starch content.

\subsection{Starch damage}

Damaged starch was measured in triplicate according to the damaged starch assay (Megazyme, AACC method 76-31). The method relies on the enzymic degradation of the damaged granules by $\alpha$-amylase and glucoamylase, while at the same time minimizing the degradation of intact granules, followed by quantification of the released glucose units by GOPOD.

\subsection{Nitrogen content}

Nitrogen was determined in triplicate using an adaptation of the AOAC official Dumas combustion method (AOAC, 1995) to an automated Dumas protein analysis system (EAS, VarioMax N/CN, Elt, Gouda, The Netherlands).

\subsection{Glucose-6-phosphate content}

Glucose-6-phosphate (glc-6-P) content was determined based on Bay-Smidt, Wischmann, Olsen, and Nielsen (1994) with slight modifications. Deionised water $(5.0 \mathrm{ml})$ was added to $150.0 \mathrm{mg}$ starch and the suspension was heated at $100{ }^{\circ} \mathrm{C}$ for $90 \mathrm{~s}$ under vigorous mixing followed by the addition of $\alpha$-amylase solution [6 $\mathrm{U}$ in $20 \mu \mathrm{l} 5.0 \mathrm{mM}$ 2-morpholinoethanesulfonic acid (MES)/KOH, pH 6.4 with $4 \mathrm{mM} \mathrm{CaCl}_{2}$ ] from Bacillus licheniformis (Megazyme) and heating for $15 \mathrm{~min}$ at $100{ }^{\circ} \mathrm{C}$. After centrifugation (3000 g, $10 \mathrm{~min}$ ), $1.0 \mathrm{ml}$ supernatant of each sample was acid hydrolysed for $240 \mathrm{~min}$ at $100{ }^{\circ} \mathrm{C}$ by addition of $62 \mu \mathrm{l}$ concentrated $\mathrm{HCl}$. Next, glc-6-P and total glucose contents of the hydrolysed samples were determined. For glc-6-P content, $10 \mathrm{mg}$ activated carbon was added to the hydrolysed samples followed by centrifugation (12000 g, $30 \mathrm{~s}$ ). In a microplate, $250 \mu \mathrm{l}$ of a $270 \mathrm{mM}$ solution of $\mathrm{K}_{2} \mathrm{HPO}_{4}$ containing $135 \mathrm{mM} \mathrm{KOH}$ and $10 \mu \mathrm{l}$ of $40 \mathrm{mM} \beta$-nicotinamide adenosine dinucleotide $\left(\mathrm{NAD}^{+}\right.$) [in $50 \mathrm{mM}$ 3-morpholinopropane-1-sulfonic acid (MOPS)/KOH buffer, pH 7.3] were added to $100 \mu$ l supernatant. A standard curve was constructed for a concentration range of 0 $0.1 \mathrm{mg} / \mathrm{ml}$ glc-6-P. Before and after addition of glc-6-P dehydrogenase from Leuconostoc mesenteroides (1 U) and thorough mixing, absorbance at $340 \mathrm{~nm}$ was measured. Analyses were performed in sixfold.

For the determination of glucose content, each hydrolysed sample was centrifuged (13000 g, $1 \mathrm{~min}$ ). Next, $750 \mu \mathrm{l}$ supernatant was neutralized with $0.7 \mathrm{M} \mathrm{KOH}$ solution $(750 \mu \mathrm{l})$ and the neutralized sample was diluted 200 times. In a microtiter plate, $220 \mu \mathrm{l} \mathrm{MOPS/KOH}$ buffer ( $50 \mathrm{mM}$, pH 7.3, $5.0 \mathrm{mM} \mathrm{MgCl}_{2}, 1.0 \mathrm{mM}$ EDTA disodium salt) was added to $100 \mu \mathrm{l}$ sample or $100 \mu$ l glucose solution (standard curve, $0-0.1 \mathrm{mg} / \mathrm{ml}$ ), followed by addition of $10 \mu \mathrm{l}$ of adenosine triphosphate solution $(100 \mathrm{mM}), 10 \mu \mathrm{NAD}^{+}$ solution $(10 \mathrm{mM})$ and a solution of hexokinase from Saccharomyces cerevisiae $(10 \mathrm{U})$. Before and after addition of glc-6-P dehydrogenase from $L$. mesenteroides ( $1 \mathrm{U}$ ) and thorough mixing, absorbance at $340 \mathrm{~nm}$ was measured. Starch contents were calculated as 0.9 times the glucose levels. Analyses were performed in sixfold. The glc-6-P content was expressed as nmol glc-6-P/mg starch.

\subsection{Granular structure}

The granule size distribution of the potato starches was determined with laser diffraction particle sizing (Malvern Mastersizer S, Goffin Meyvis, Bergen op Zoom, The Netherlands). The wet sample dispersion unit was used and information was obtained from 64 channels over a particle size range of $0.05-900 \mu \mathrm{m}$. The results were expressed in volume percentage (\%), using Mastersizer S Version 3.1 software (1996).

For the Scanning Electron Microscopy (SEM) analyses, starch was deposited on a stub and sputter coated with gold (SPI-MODULE TM Sputter Coater, SPI Supplies, West Chester, PA, USA). The samples were analysed using a JSM-6360 scanning electron microscopy (JEOL, Peabody, MA, USA) at $10 \mathrm{kV}$. 


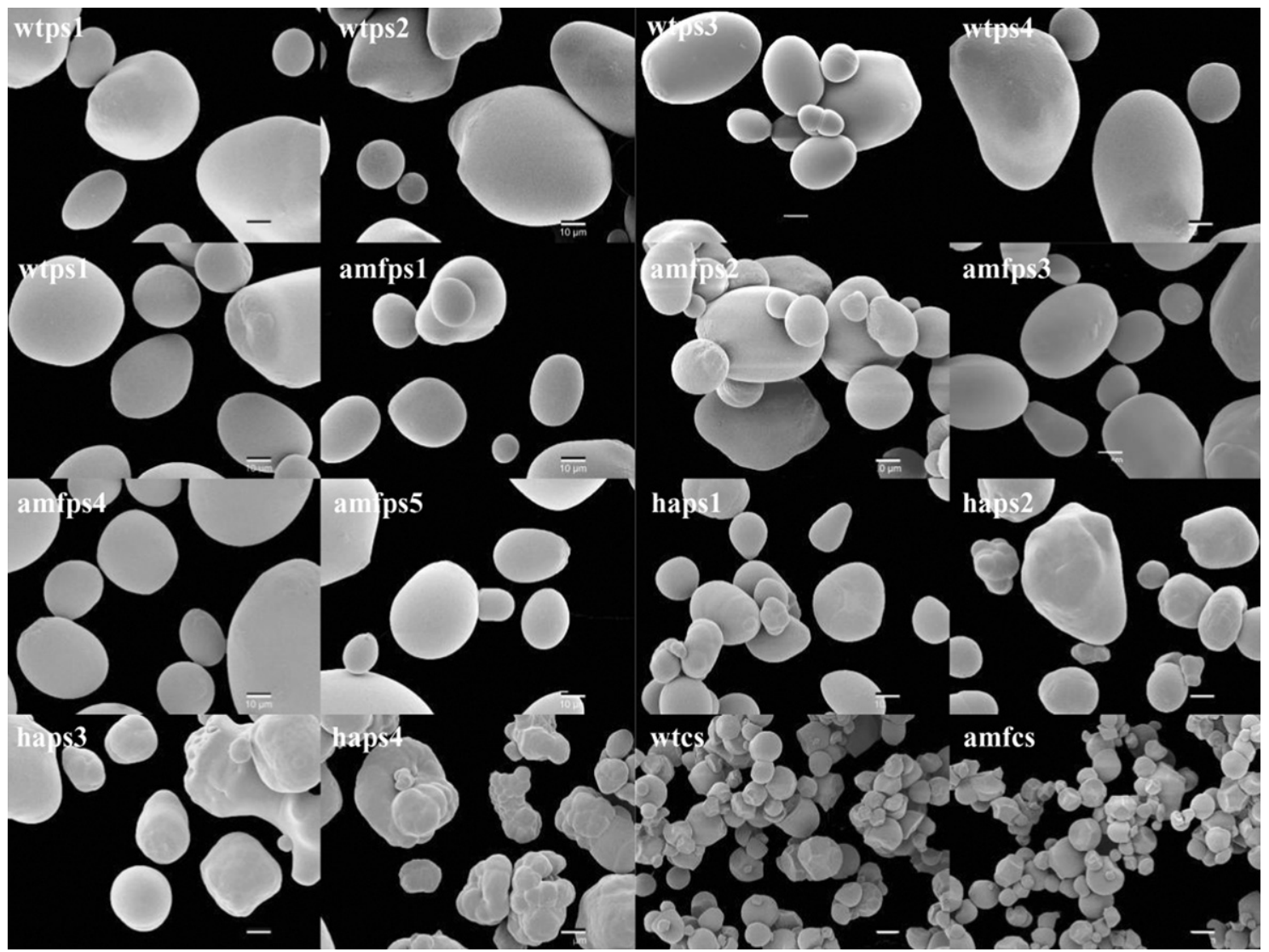

Fig. 2. Scanning electron microscopy images of the starch granules of intact wild type (wt), amylose free (amf) and high-amylose (ha) potato (p) and cassava (c) starches (s).

\subsection{Relative crystallinity}

Wide angle X-ray diffraction (WAXD) measurements were performed with Ni-filtered $\mathrm{Cu} \kappa \alpha$ radiation on a Rigaku rotating anode device (Rigaku, Tokyo, Japan) operating at $40 \mathrm{kV}$ and $100 \mathrm{~mA}$, using a Rigaku high temperature X-ray diffractometer (Rigaku). Detection was with a scintillation counter with a powder diffractometer operating in transmission mode. Starches were first equilibrated for $48 \mathrm{~h}$ in a humifidier ( $20 \pm 2 \%$ final moisture content). Highly crystalline A- and B-type starches were prepared by acid hydrolysis
(2.2 $\mathrm{M} \mathrm{HCl}$ ) of waxy maize starch and high-AM maize starch, respectively, for 6 weeks at $37{ }^{\circ} \mathrm{C}$ with regular gentle shaking. The suspensions were filtered and the solids washed with deionised water until the $\mathrm{pH}$ was neutral followed by air-drying.

An amorphous sample was prepared by freeze drying potato starch, gelatinised in excess water. Starch was enclosed in aluminium foil and scattering patterns were measured in 6.5-33 range with a fixed time of $10 \mathrm{~s}$ per step of $0.05^{\circ}$. Data were normalised after measurements. Differences between two measurements were less than $5.0 \%$. The relative crystallinity (RC) was

Table 3

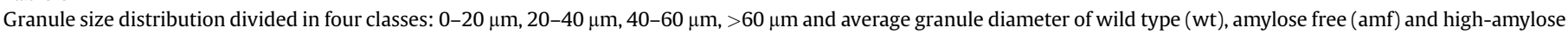
(ha) potato (p) and cassava (c) starches (s).

\begin{tabular}{|c|c|c|c|c|c|}
\hline Sample & $0-20 \mu \mathrm{m}(\%)$ & $20-40 \mu \mathrm{m}(\%)$ & $40-60 \mu \mathrm{m}(\%)$ & $>60 \mu \mathrm{m}(\%)$ & average diameter $(\mu \mathrm{m})$ \\
\hline wtps1 & 6.3 & 25.6 & 42.8 & 25.4 & 52.4 \\
\hline wtps2 & 6.9 & 23.1 & 39.6 & 30.4 & 55.2 \\
\hline wtps3 & 8.2 & 33.1 & 40.9 & 17.8 & 47.5 \\
\hline wtps4 & 6.2 & 18.6 & 36.9 & 38.3 & 59.6 \\
\hline wtps5 & 8.5 & 27.9 & 40.8 & 22.8 & 50.3 \\
\hline amfps1 & 10.1 & 33.5 & 37.6 & 18.8 & 47.2 \\
\hline amfps2 & 11.3 & 28.2 & 34.6 & 25.9 & 51.2 \\
\hline amfps3 & 8.1 & 33.0 & 43.7 & 15.2 & 46.3 \\
\hline amfps4 & 10.0 & 32.3 & 40.8 & 16.6 & 53.7 \\
\hline amfps5 & 5.9 & 23.8 & 42.4 & 27.8 & 53.8 \\
\hline haps1 & 19.4 & 44.2 & 28.4 & 8.0 & 37.5 \\
\hline haps2 & 15.8 & 38.4 & 32.6 & 13.2 & 41.9 \\
\hline haps3 & 18.1 & 41.0 & 29.9 & 11.1 & 39.8 \\
\hline haps4 & 22.0 & 50.7 & 23.8 & 3.5 & 33.7 \\
\hline wtcs & 81.1 & 18.3 & 0.6 & 0.0 & 18.0 \\
\hline amfcs & 84.2 & 15.3 & 0.5 & 0.0 & 16.9 \\
\hline
\end{tabular}



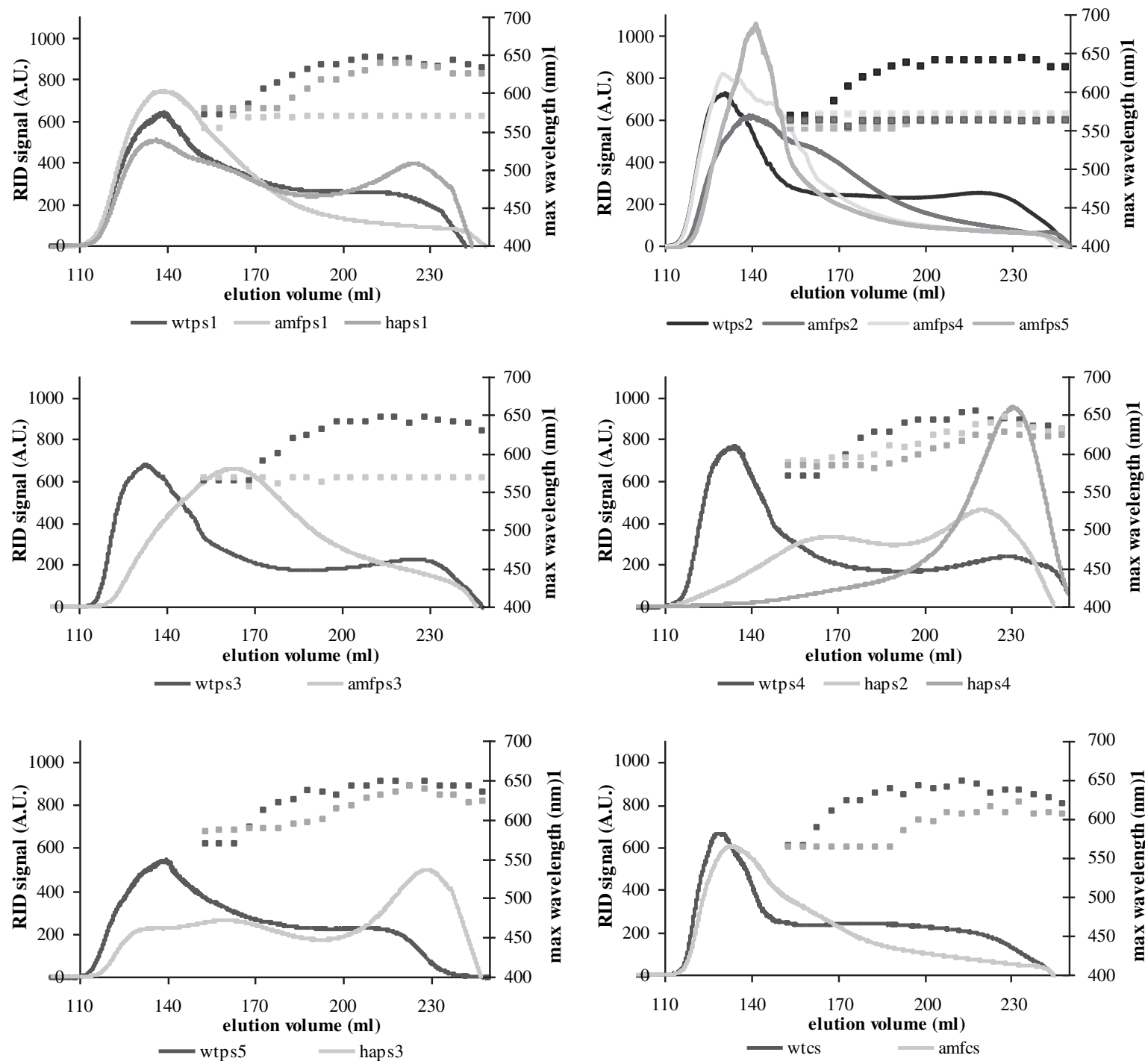

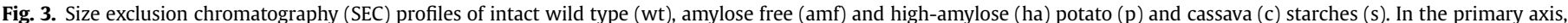
refractive index detector (RID) signal is given and in the secondary axis, the maximum wavelength (nm) is shown.

calculated according to Wakelin, Virgin, and Crystal (1959) and is given by

relative crystallinity $=\frac{\sum_{i}\left|(\mathrm{Is}-\mathrm{Ia})_{i}\right|}{\sum_{i}\left|(\mathrm{Ic}-\mathrm{Ia})_{i}\right|}$

with

Is: intensity of the sample for each diffraction angle

Ia: intensity of an amorphous sample for each diffraction angle Ic: intensity of a high crystalline A-type and B-type crystals for each diffraction angle for cassava starch and potato starch, respectively.

\subsection{Molecular distribution of amylopectin and amylose}

AP and AM were separated by size exclusion chromatography (SEC) after starch solubilisation. Samples (30 mg, accurately weighed) were solubilised in $1.0 \mathrm{ml} \mathrm{KOH}$ solution $(0.2 \mathrm{M})$ by heating for $5 \mathrm{~min}$ at $95{ }^{\circ} \mathrm{C}$, followed by diluting to $20.0 \mathrm{ml}$ with deionised water. These conditions resulted in at least 95\% starch solubilisation [assessed according to Dubois, Gilles, Hamilton, Rebers, and Smith (1956)] with minimal degradation. After filtration $(0.45 \mu \mathrm{m}), 5.0 \mathrm{ml}$ of the solubilised sample was applied on a Toyopearl HW-75F gel $(600 \times 26 \mathrm{~mm})$ (TosoHaas, Stuttgart, Germany) at $50{ }^{\circ} \mathrm{C}$ (Blennow, Bay-Smidt, \& Bauer, 2001). A Biologic Duo Flow Core System (Bio-Rad Laboratories, Hercules, CA, USA), equipped with a refractive index detector (RID-10A, Shimadzu, Kyoto, Japan), was used. Elution was with $0.01 \mathrm{M} \mathrm{KOH}$ solution (containing $0.02 \%$ sodium azide) at a flow rate of $0.75 \mathrm{ml} / \mathrm{min}$. Fractions $(5.0 \mathrm{ml})$ were collected and their iodine binding was measured by mixing $1.8 \mathrm{ml}$ of the fraction with $0.1 \mathrm{ml} \mathrm{HCl}$ solution $(1.0 \mathrm{M})$ and $0.1 \mathrm{ml} \mathrm{KI} / \mathrm{I}_{2}$ solution $\left(0.90 \mathrm{mg} \mathrm{KI} / \mathrm{ml}\right.$ and $\left.0.38 \mathrm{mg} \mathrm{I}_{2} / \mathrm{ml}\right)$. After 30 min incubation at room temperature, the fractions were spectrophotometrically scanned (500-800 nm wavelength range).

\subsection{Chain length distribution analysis}

Enzymatically debranched starches were prepared based on Umemoto, Nakamura, Satoh, and Terashima (1999) with slight 

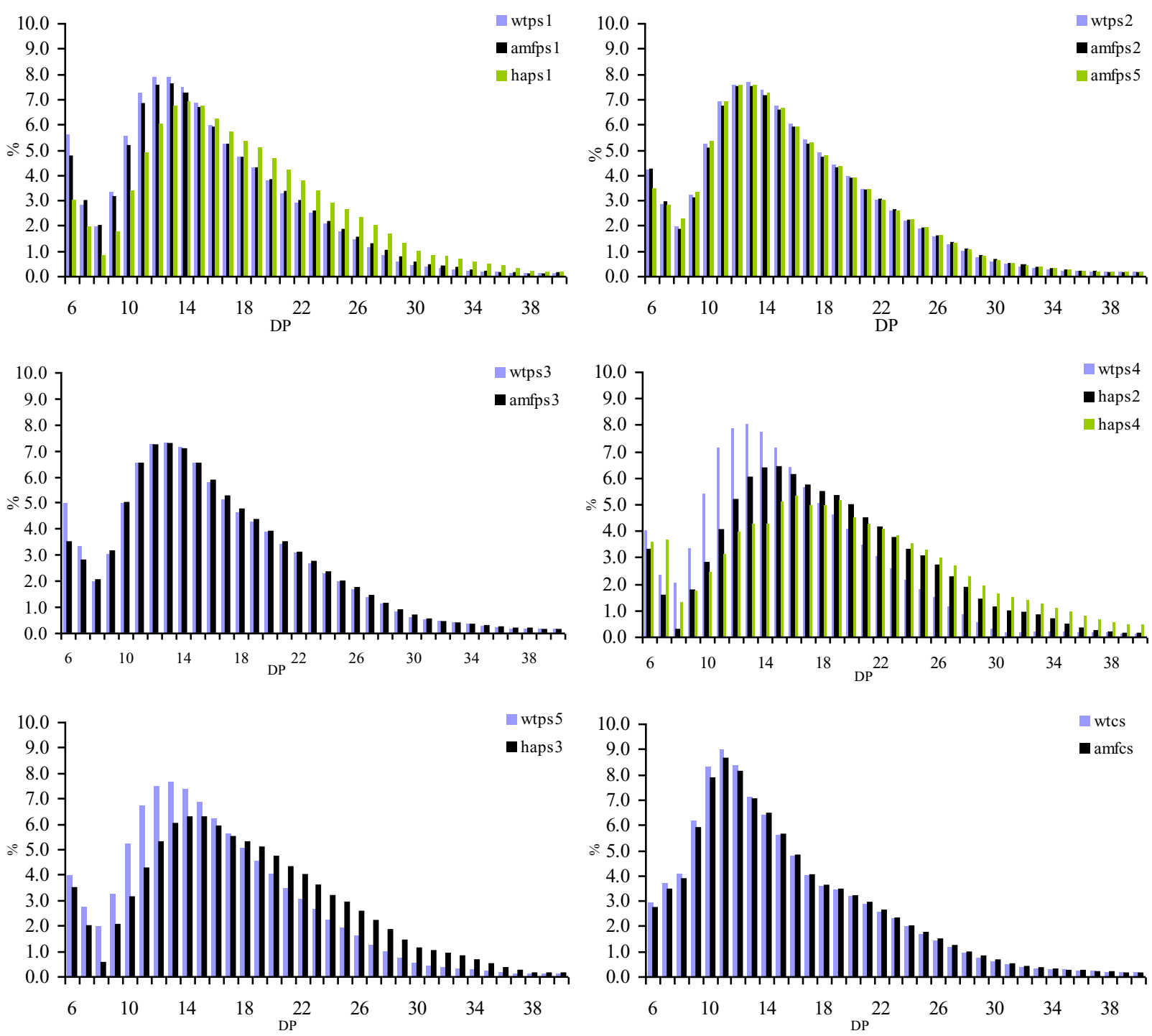

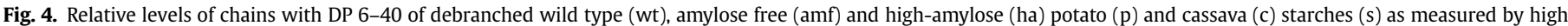
performance anion-exchange chromatography (HPAEC) profiles.

modifications. Starch (10.0 mg) was suspended in $5.0 \mathrm{ml}$ water and boiled $(60 \mathrm{~min})$ to gelatinise the starch. Sodium acetate buffer ( $50 \mu \mathrm{l}, 600 \mathrm{mM}, \mathrm{pH} 4.6$ ) and $10 \mu \mathrm{l}$ of $2.0 \%$ (w/v) sodium azide were added to the samples $(1.0 \mathrm{ml})$. Isoamylase from Pseudomonas amylodermosa (12 U, Megazyme) was used to debranch the sample for $24 \mathrm{~h}$ at $40{ }^{\circ} \mathrm{C}$. The enzyme was then inactivated by heating $\left(100{ }^{\circ} \mathrm{C}, 10 \mathrm{~min}\right)$. A second incubation for $24 \mathrm{~h}$ at $40{ }^{\circ} \mathrm{C}$ was performed after adding the same isoamylase (12 U). After heating $\left(100{ }^{\circ} \mathrm{C}, 10 \mathrm{~min}\right)$, cooled samples were filtered $(0.22 \mu \mathrm{m})$ and analysed with high performance anion-exchange chromatography (HPAEC) with pulsed amperometric detection (PAD), using Carbopac PA-100 Guard and Carbopac PA-100 anion-exchange $(250 \mathrm{~mm} \times 4 \mathrm{~mm})$ columns. The eluents and the eluent gradient program were as described by Jacobs, Eerlingen, Rouseu, Colonna, and Delcour (1998). Individual peaks in the chromatograms were corrected for molar PAD detector responses (Koch, Andersson, \& Aman, 1998). Analyses were performed at least in quadruplicate. The coefficient of variation for the measurements did not exceed $5 \%$. The relative amounts of AP chains were normalised and divided into five fractions: DP 6-9, DP 10-14, DP 15-17, DP 18-25 and $\mathrm{DP}>25$.
Enzymatically debranched starches were prepared for high performance size exclusion chromatography (HPSEC) based on Klucinec and Thompson (1998) with slight modifications. Starch (5.0 mg) was dissolved in $120 \mu \mathrm{l}$ DMSO (90\%) with thorough mixing for $10 \mathrm{~min}$ at $100{ }^{\circ} \mathrm{C}$. After addition of $880 \mu$ l sodium acetate buffer (100 mM, pH 4.5), the suspension was heated again for $10 \mathrm{~min}$ at $100{ }^{\circ} \mathrm{C}$. After cooling, $50 \mu \mathrm{l}$ solution of the above isoamylase (1250 U), dissolved in sodium acetate buffer ( $100 \mathrm{mM}$, pH 4.5), was added and the samples were incubated for $12 \mathrm{~h}$ at $40{ }^{\circ} \mathrm{C}$. The enzyme was inactivated by heating for $10 \mathrm{~min}$ at $100{ }^{\circ} \mathrm{C}$. A second incubation for $12 \mathrm{~h}$ at $40^{\circ} \mathrm{C}$ was performed after renewed addition of the same isoamylase (625 $\mathrm{U})$. After inactivation of isoamylase $\left(10 \mathrm{~min}, 100{ }^{\circ} \mathrm{C}\right)$, the sample was filtered $(0.45 \mu \mathrm{m})$ and injected. The HPSEC system consisted of a pump (LC-20AD/LC-20AT, Shimadzu), an injector (SIL-20A autoinjector, Shimadzu) and a RID10A. Two Zorbax PSM 60S columns $(6.2 \times 250 \mathrm{~mm})$, packed with $5 \mu \mathrm{m}$ porous silica microspheres (Agilent Technologies, Wilmington, DE, USA) connected in series, were used. These columns were maintained at $50{ }^{\circ} \mathrm{C}$ using a column oven (CTO-20AC, Shimadzu), while the detector was maintained at $40^{\circ} \mathrm{C}$. The mobile phase was on-line degassed (DGU-20 A5, Shimadzu) DMSO (90\%). The flow 
Table 4

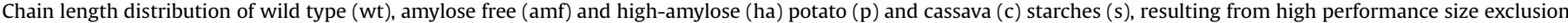

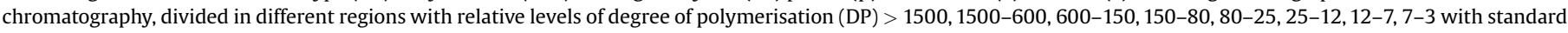
deviation between brackets.

\begin{tabular}{|c|c|c|c|c|c|c|c|c|c|}
\hline \multirow[b]{2}{*}{ Sample } & & \multicolumn{3}{|c|}{ amylose chains + long B chains } & \multirow{2}{*}{$\frac{\text { B4 chains }}{150-80}$} & \multirow{2}{*}{$\frac{\mathrm{B} 2+\mathrm{B} 3 \text { chains }}{80-25}$} & \multicolumn{3}{|c|}{$A+B 1$ chains } \\
\hline & & $>1500$ & $1500-600$ & $600-150$ & & & $25-12$ & $12-7$ & $7-3$ \\
\hline \multirow[t]{2}{*}{ wtps1 } & $\mathrm{DP}_{\mathrm{w}}^{1}$ & $2.7(0.5)$ & $4.4(0.4)$ & $13.5(1.2)$ & $5.3(0.6)$ & $18.1(0.5)$ & $27.7(1.4)$ & $20.9(0.8)$ & $2.4(0.3)$ \\
\hline & $\mathrm{DP}_{\mathrm{n}}^{2}$ & $0.0(0.0)$ & $0.1(0.0)$ & $1.0(0.1)$ & $0.9(0.1)$ & $8.6(0.4)$ & $37.1(1.2)$ & $44.7(0.6)$ & $7.6(1.2)$ \\
\hline \multirow[t]{2}{*}{ wtps2 } & $\mathrm{DP}_{\mathrm{w}}^{1}$ & $1.9(0.1)$ & $2.6(0.6)$ & 10.5 & $5.7(0.2)$ & $21.7(0.0)$ & $28.9(0.7)$ & $20.2(0.0)$ & $2.1(0.3)$ \\
\hline & $\mathrm{DP}_{\mathrm{n}}^{2}$ & $0.0(0.0)$ & $0.1(0.0)$ & $0.9(0.3)$ & $1.1(0.2)$ & $10.7(0.3)$ & $38.3(1.0)$ & $42.7(0.6)$ & $6.3(1.1)$ \\
\hline \multirow[t]{2}{*}{ wtps3 } & $\mathrm{DP}_{\mathrm{w}}^{1}$ & $3.2(0.3)$ & $3.0(0.4)$ & $13.5(0.6)$ & $5.7(0.5)$ & $19.8(0.5)$ & $26.6(1.0)$ & $19.0(1.6)$ & $2.2(0.1)$ \\
\hline & $\mathrm{DP}_{\mathrm{n}}^{2}$ & $0.0(0.0)$ & $0.1(0.0)$ & $1.0(0.1)$ & $1.0(0.1)$ & $9.8(0.6)$ & $37.6(0.4)$ & $43.5(1.0)$ & $7.2(0.2)$ \\
\hline \multirow[t]{2}{*}{ wtps4 } & $\mathrm{DP}_{\mathrm{w}}^{1}$ & $4.0(0.6)$ & $5.0(1.0)$ & $15.1(2.1)$ & $5.3(0.6)$ & $18.2(1.0)$ & $26.5(2.1)$ & $18.0(1.8)$ & $1.7(0.1)$ \\
\hline & $\mathrm{DP}_{\mathrm{n}}^{2}$ & $0.0(0.0)$ & $0.1(0.0)$ & $1.2(0.5)$ & $0.9(0.5)$ & $9.0(0.5)$ & $40.3(0.8)$ & $43.4(2.8)$ & $5.1(1.2)$ \\
\hline \multirow[t]{2}{*}{ wtps5 } & $\mathrm{DP}_{\mathrm{w}}^{1}$ & $2.1(0.3)$ & $2.3(0.3)$ & $8.6(0.5)$ & $3.6(0.5)$ & $18.7(0.3)$ & $33.3(1.8)$ & $23.9(1.1)$ & $2.4(0.2)$ \\
\hline & $\mathrm{DP}_{\mathrm{n}}^{2}$ & $0.0(0.0)$ & $0.1(0.0)$ & $0.7(0.2)$ & $0.8(0.3)$ & $9.9(0.6)$ & $39.5(0.6)$ & $42.8(0.5)$ & $6.2(0.9)$ \\
\hline \multirow[t]{2}{*}{ amfps1 } & $\mathrm{DP}_{\mathrm{w}}^{1}$ & $2.2(0.3)$ & $2.9(0.4)$ & $9.3(0.1)$ & $7.0(0.2)$ & $22.0(1.1)$ & $27.4(1.4)$ & $19.3(0.5)$ & $2.1(0.0)$ \\
\hline & $\mathrm{DP}_{\mathrm{n}}^{2}$ & $0.0(0.0)$ & $0.1(0.0)$ & $0.6(0.1)$ & $1.2(0.1)$ & $10.5(0.7)$ & $37.7(0.9)$ & $43.3(1.5)$ & $6.7(0.5)$ \\
\hline \multirow[t]{2}{*}{ amfps2 } & $\mathrm{DP}_{\mathrm{w}}^{1}$ & $1.5(0.1)$ & $1.8(0.4)$ & $7.1(0.9)$ & $8.0(1.7)$ & $25.3(1.6)$ & $28.4(0.7)$ & $20.3(0.9)$ & $2.3(0.4)$ \\
\hline & $\mathrm{DP}_{\mathrm{n}}^{2}$ & $0.0(0.0)$ & $0.0(0.0)$ & $0.5(0.1)$ & $1.5(0.4)$ & $11.9(1.0)$ & $36.7(0.4)$ & $42.4(0.6)$ & $7.0(1.3)$ \\
\hline \multirow[t]{2}{*}{ amfps3 } & $\mathrm{DP}_{\mathrm{w}}^{1}$ & $2.5(0.5)$ & $1.7(0.2)$ & $11.7(0.2)$ & $12.3(0.8)$ & $20.8(1.3)$ & $22.2(0.4)$ & $17.8(1.2)$ & $1.9(0.0)$ \\
\hline & $\mathrm{DP}_{\mathrm{n}}^{2}$ & $0.0(0.0)$ & $0.0(0.0)$ & $1.1(0.0)$ & $2.9(0.1)$ & $11.1(0.4)$ & $34.6(0.3)$ & $43.9(0.8)$ & $6.3(0.2)$ \\
\hline \multirow[t]{2}{*}{ amfps4 } & $\mathrm{DP}_{\mathrm{w}}^{1}$ & $2.2(0.3)$ & $2.0(0.4)$ & $8.7(0.9)$ & $9.5(0.8)$ & $23.3(1.9)$ & $25.9(1.7)$ & $19.7(1.9)$ & $2.0(0.2)$ \\
\hline & $\mathrm{DP}_{\mathrm{n}}^{2}$ & $0.0(0.0)$ & $0.0(0.0)$ & $0.6(0.1)$ & $1.9(0.3)$ & $10.3(0.2)$ & $34.7(1.3)$ & $45.7(0.3)$ & $6.7(0.8)$ \\
\hline \multirow[t]{2}{*}{ amfps5 } & $\mathrm{DP}_{\mathrm{w}}^{1}$ & $2.2(0.4)$ & $2.2(0.8)$ & $8.0(1.6)$ & $5.6(0.8)$ & $22.6(0.8)$ & $29.6(2.0)$ & $21.6(1.5)$ & $2.4(0.3)$ \\
\hline & $\mathrm{DP}_{\mathrm{n}}^{2}$ & $0.0(0.0)$ & $0.0(0.0)$ & $0.5(0.1)$ & $0.9(0.2)$ & $10.4(0.3)$ & $37.2(0.9)$ & $43.8(1.0)$ & $7.2(1.3)$ \\
\hline \multirow[t]{2}{*}{ haps1 } & $\mathrm{DP}_{\mathrm{w}}^{1}$ & $24.7(1.2)$ & $10.9(0.3)$ & $16.9(1.0)$ & $5.7(0.1)$ & $12.1(0.5)$ & $21.1(1.4)$ & $7.9(0.4)$ & $0.8(0.1)$ \\
\hline & $\mathrm{DP}_{\mathrm{n}}^{2}$ & $0.2(0.0)$ & $0.4(0.1)$ & $2.8(0.2)$ & $1.9(0.2)$ & $13.7(1.6)$ & $48.1(1.7)$ & 32.9 (2.9) & $0.0(0.0)$ \\
\hline \multirow[t]{2}{*}{ haps2 } & $\mathrm{DP}_{\mathrm{w}}^{1}$ & $26.9(0.9)$ & $13.5(0.2)$ & $23.9(0.1)$ & $5.6(0.1)$ & $10.0(0.1)$ & $14.4(0.2)$ & $5.7(0.9)$ & $0.1(0.0)$ \\
\hline & $\mathrm{DP}_{\mathrm{n}}^{2}$ & $0.3(0.0)$ & $0.7(0.1)$ & $4.7(0.3)$ & $2.7(0.1)$ & $13.4(0.7)$ & $47.8(2.1)$ & $30.3(0.0)$ & $0.0(0.0)$ \\
\hline \multirow[t]{2}{*}{ haps3 } & $\mathrm{DP}_{\mathrm{w}}^{1}$ & $29.4(1.3)$ & $12.7(0.6)$ & $25.2(3.4)$ & $6.3(0.3)$ & $8.9(0.8)$ & $11.7(0.9)$ & $4.3(0.9)$ & $0.0(0.0)$ \\
\hline & $\mathrm{DP}_{\mathrm{n}}^{2}$ & $0.4(0.0)$ & $0.8(0.0)$ & $5.9(1.3)$ & $3.5(0.1)$ & $13.0(0.3)$ & $47.1(1.3)$ & $29.4(1.2)$ & $0.0(0.0)$ \\
\hline \multirow[t]{2}{*}{ haps4 } & $\mathrm{DP}_{\mathrm{w}}^{1}$ & $24.4(1.1)$ & $10.2(0.1)$ & $44.1(0.0)$ & $11.5(0.4)$ & $6.1(0.5)$ & $3.2(0.2)$ & $0.7(0.0)$ & $0.0(0.0)$ \\
\hline & $\mathrm{DP}_{\mathrm{n}}^{2}$ & $0.6(0.0)$ & $1.6(0.0)$ & $26.4(1.0)$ & $14.7(0.1)$ & $20.1(0.9)$ & $27.4(0.4)$ & $9.3(0.2)$ & $0.0(0.0)$ \\
\hline \multirow[t]{2}{*}{ wtcs } & $\mathrm{DP}_{\mathrm{w}}^{1}$ & $2.4(1.0)$ & $2.8(0.4)$ & $7.1(1.1)$ & $3.4(0.2)$ & $20.3(0.5)$ & $30.1(1.2)$ & $27.7(0.9)$ & $3.5(0.0)$ \\
\hline & $\mathrm{DP}_{\mathrm{n}}^{2}$ & $0.0(0.0)$ & $0.0(0.0)$ & $0.4(0.1)$ & $0.5(0.1)$ & $8.6(0.2)$ & $32.0(0.4)$ & $49.1(0.6)$ & $9.4(0.5)$ \\
\hline \multirow[t]{2}{*}{ amfcs } & $\mathrm{DP}_{\mathrm{w}}^{1}$ & $0.6(0.1)$ & $0.8(0.2)$ & $3.6(0.1)$ & $4.8(0.2)$ & $24.5(0.1)$ & $33.1(0.1)$ & $28.9(0.5)$ & $3.3(0.2)$ \\
\hline & $\mathrm{DP}_{\mathrm{n}}^{2}$ & $0.0(0.0)$ & $0.0(0.0)$ & $0.2(0.0)$ & $0.7(0.0)$ & $9.8(0.0)$ & $33.1(0.0)$ & $47.6(0.7)$ & $8.6(0.7)$ \\
\hline
\end{tabular}

$\mathrm{DP}_{\mathrm{w}}^{1}$ : chain length distribution levels expressed on weight basis in percent.

$\mathrm{DP}_{\mathrm{n}}^{2}$ : chain length distribution levels expressed on number basis in percent.

rate was $0.5 \mathrm{ml} / \mathrm{min}$ and the injection volume was $50 \mu \mathrm{l}$. Separate injections of the following standards $(50 \mu \mathrm{l})$ were performed: glucose $[(\mathrm{MW})=180, \mathrm{DP} 1]$, maltose $(\mathrm{MW}=342$, DP 2), maltotriose $(\mathrm{MW}=504$, DP 3), maltopentaose (MW = 829, DP 5), maltoheptaose (MW $=1153$, DP 7) and Shodex pullulan standards (Showa Denko, Munich, Germany) with MWs of $5.9 \times 10^{3}$ (DP 5), $11.8 \times 10^{3}($ DP 10$), 22.8 \times 10^{3}\left(\right.$ DP 20) and $47.3 \times 10^{3}$ (DP 50). In order to obtain molar-based chromatograms, the differential refractive index response at each time was divided by the MW of the carbohydrates eluting at that time. The chromatograms were divided into 8 regions based on the retention times of the minima (I-VII) or the inflection point (VII-VIII). DP limits of the different regions were: I (DP > 1500), II (DP 1500-600), III (DP 600-150), IV (DP 150-80), V (DP 80-25), VI (DP 25-12), VII (DP 12-7), VIII (DP 73). Regions I, II and III correspond to the AM molecules and very long $B$ chains of $A P$, regions IV and $V$ to long $B$ chains and regions VI-VIII to A and B1 chains (Hizukuri, 1986).

The total carbohydrate content was measured by the phenol sulfuric acid method (Dubois et al., 1956) and the concentration of reducing groups was determined using the method described by Waffenschmidt and Jaenicke (1987).

\subsection{Differential Scanning Calorimetry}

Differential Scanning Calorimetry (DSC) was carried out with a Q1000 DSC (TA instruments, New Castle, DE, USA). Starch (4.00$6.00 \mathrm{mg}$ ) was accurately weighed in an aluminium pan (Perkin Elmer, Waltham, MA, USA) and deionised water was added [1:3 w/w starch dry matter $(\mathrm{dm})$ :water]. The pans were hermetically sealed and equilibrated for at least $20 \mathrm{~min}$. The pans were heated from $20^{\circ} \mathrm{C}$ to $130{ }^{\circ} \mathrm{C}$ at $4{ }^{\circ} \mathrm{C} / \mathrm{min}$ and an empty pan was used as reference. Calibration was with indium. Analyses were performed at least in triplicate. The onset $\left(T_{0}\right)$, peak $\left(T_{\mathrm{p}}\right)$, conclusion temperature $\left(T_{\mathrm{c}}\right)$ and enthalpy $(\Delta H)$ were determined using TA Universal Analysis software. Temperature was expressed in ${ }^{\circ} \mathrm{C}$ and enthalpy in J/g. Gelatinisation temperature range is the difference between $T_{\mathrm{C}}$ and $T_{0}$.

\subsection{Statistical analyses}

Pearson's correlation coefficient analyses were performed (significance level $P<0.05$ ). Statistical analyses were conducted using the Statistical Analysis System software 8.1 (SAS Institute, Cary, NC, USA). The statistical analyses were performed for wtps 


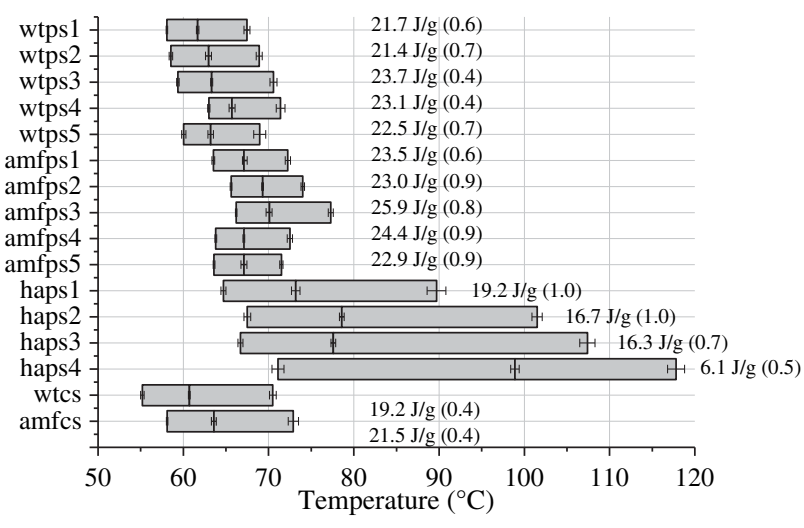

Fig. 5. Schematic overview of the gelatinisation characteristics of intact wild type (wt), amylose free (amf) and high-amylose (ha) potato (p) and cassava (c) starches (s). Start and end point of the bars represent onset $\left(T_{\mathrm{o}}\right)$ and conclusion $\left(T_{\mathrm{c}}\right)$ temperatures of gelatinisation. The vertical line inside the bar is the peak temperature $\left(T_{\mathrm{p}}\right)$. Gelatinisation enthalpies $(\Delta H)$ are given with standard deviations between brackets.

and amfps samples (further referred as $n=10$ ), wtps, amfps and haps samples $(n=14)$ and all starches $(n=16)$. haps samples were excluded in specific cases because they were bad leverage points. Cassava starches were excluded in the statistical analyses of RC because of their different crystal type.

\section{Results and discussion}

\subsection{Starch structure}

\subsubsection{Starch characterisation}

Table 2 shows AM and glc-6-P contents and the levels of damaged starch for all starches. The potato and cassava starches had a wide range of AM contents (3.2-78.4\%; 6.0-18.4\%, respectively). Low levels of AM were also detected in amfps samples. These low levels were probably overestimated because of the interference by poorly branched low-MW AP (Gerard, Barron, Colonna, \& Planchot, 2001). All starches had a low damaged starch levels $(<1.3 \%$ ), and were of high purity (nitrogen content $<0.01 \%$ $\mathrm{dm}$, results not shown). Glc-6-P contents are largely linearly correlated with total starch phosphorylation level (Bay-Smidt, Blennow, Bojko, \& Moller, 1999). The different wild type samples (wtps1-wtps5) had a broad range of glc-6-P contents (9.2$20.4 \mathrm{nmol} / \mathrm{mg}$ starch), in agreement with Bay-Smidt et al. (1994). Apart from amfps3, amfps had slightly higher glc-6-P contents than their parent starches. The small increase in glc-6-P content is

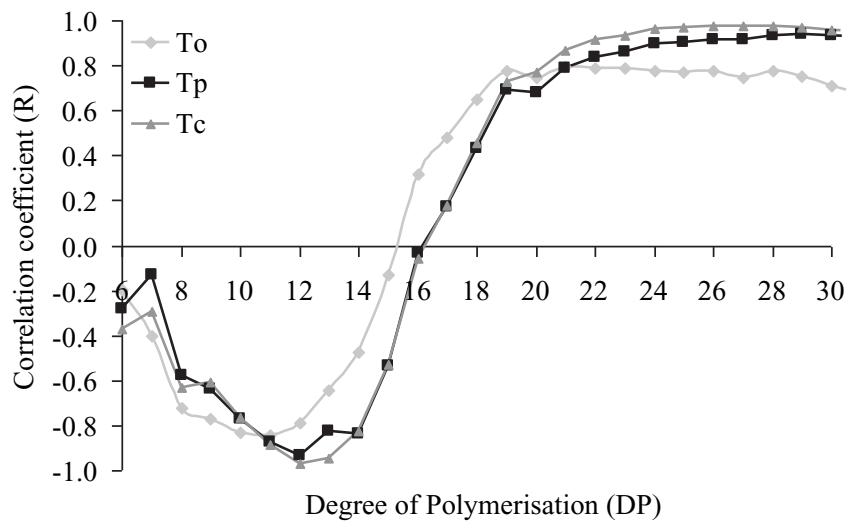

Fig. 6. Plot of correlation coefficients between the level of chains with degree of polymerisation (DP) 6-30 and the onset $\left(T_{0}\right)$, peak $\left(T_{\mathrm{p}}\right)$ and conclusion $\left(T_{\mathrm{c}}\right)$ temperature of gelatinisation as a function of DP. probably due to the increased AP content. However, haps samples had the lowest AP levels and showed the highest degree of starch glucose-6-phosphorylation. This may be explained by their higher levels of longer AP chains than in wtps AP (cf. infra). In this respect, Mikkelsen, Baunsgaard, and Blennow (2004) reported a higher degree of in vitro phosphorylation of longer (DP 30-100) than of shorter (DP < 30) AP chains. Linear AM is a poor substrate for $\alpha$-glucan water dikinase, the enzyme responsible for phosphorylation, due to the absence of $\alpha-(1,6)$ bonds (Mikkelsen et al., 2004). Schwall et al. (2000) also found higher levels of AP chains with DP $>20$ in high-AM starches. As expected, no glc-6-P ester groups were detected in cassava starches.

\subsubsection{Granular structure}

Fig. 2 shows SEM pictures of the starch granules. wtps and amfps granules had oval to spherical shapes and a smooth surface with only few irregularities. The size distribution of the granules was heterogeneous for all starches. No pores were observed at the surfaces. haps samples (especially haps3 and haps4) had granule structures differing from those of wtps and amfps, as also observed by Blennow et al. (2005). These granules had irregular surfaces and fissures. These phenomena were more pronounced for the starches of highAM content. The granules of haps 4 were multi-lobed. The haps granules were also smaller than those of the other potato starches. The cassava starch granules were much smaller than potato starch granules. Most of these granules were oval to round and some granules showed a truncated end, in line with Moorthy (2002).

Table 3 lists the granule size distributions as determined using laser light scattering. The granule size distribution is unimodal for potato and cassava starches. In general, potato starch granules are large $(10-110 \mu \mathrm{m})$. For each genotype, wtps had the largest granules (mean diameter: $47.5-59.6 \mu \mathrm{m}$ ), followed by amfps (mean diameter: 46.3-53.8 $\mu \mathrm{m}$ ) and haps (mean diameter: 33.7-41.9 $\mu \mathrm{m}$ ). The granules of cassava starches were much smaller (mean diameter: 16.9$18.0 \mu \mathrm{m}$ ). These differences were also reflected in the SEM images.

\subsubsection{Molecular structure}

Fig. 3 shows the molecular size distribution of intact AP and AM together with their maximum wavelength $\left(\lambda_{\max }\right)$ after iodine binding. The iodine binding capacity of AM is ca. 20 times higher than that of AP. The wavelength for maximum extinction exceeds $620 \mathrm{~nm}$ for AM and is lower than $600 \mathrm{~nm}$ for AP (Hizukuri, 1996). Based on differences in iodine binding capacity, the profiles were divided into three sections and the relative amounts of high-MW AP (110-150 ml, region I), low-MW AP (150-190 ml, region II) and AM (190-245 ml, region III) were estimated (Table 2) as described by Schwall et al. (2000).

In contrast to wts (wtps and wtcs together), amfs (amfps and amfcs together) and haps samples showed a shoulder (elution volume of $150-170 \mathrm{ml}$ ) in their elution profiles, suggesting the presence of AP with a slightly lower average molecular size. All amfps samples except for amfps 3 contained more high-MW than low-MW AP, while the opposite was observed for haps samples (except for haps1). In this respect, haps4 with the highest AM content (78.4\%), did contain little if any high-MW AP. Shi, Capitani, Trzasko, and Jeffcoat (1998) described similar observations for very high-AM maize starch. AM contents measured by ConA were strongly correlated with those obtained by SEC $\left(R^{2}=0.94\right)$, even though AM levels of amfps and wtps were slightly higher when measured by SEC. This is probably due to the presence of relatively small AP molecules with extended A and B chains as earlier described by Morrison and Karkalas (1990).

The maximum wavelength for iodine bound starch ranged for the region I and II AP fractions from 558 to $570 \mathrm{~nm}$ and from 578 to $590 \mathrm{~nm}$ for amfps and wtps, and haps respectively. This indicated 
that haps samples had higher average AP CL than did wtps and amfps. For the AM fractions (region III), the maximum wavelength of amfps was lower than $620 \mathrm{~nm}$, confirming the absence of AM. The maximum wavelength of haps AM fractions was lower (626$640 \mathrm{~nm}$ ) than that for wtps $(642-648 \mathrm{~nm})$, indicating slight differences in the AM structures.

The CL distributions of debranched starches were analysed using HPAEC (Fig. 4) and HPSEC (Table 4). HPAEC analysis showed for all potato starches a dip for side chains with DP 8. Peak DP of wtps and amfps was DP 12-13. haps, in contrast, had a peak DP of 14-15 and the profiles showed a shoulder at DP 24-28. CL distribution of wtps and amfps hardly differed. Different amfps had slightly lower levels of short chains (DP $<14$ ) and slightly higher levels of the longer chains (DP > 18) than their corresponding wtps. CL distribution varied more with genotype than as a result of mutation. Chain length distributions of cassava starches were clearly different with a peak DP at 11 and a shoulder at DP 19-21. In addition, the cassava starches showed no dip in their CL profiles at DP 8.

The debranched starches were also analysed using HPSEC. HPAEC analyses provide only detailed information on the short chains $(\mathrm{DP}<50)$ with a high resolution where HPSEC gives complementary information on the longer chains. The HPSEC chromatograms were divided in regions based on the observed minima and inflections. Table 4 shows the mass-based and molar-based percentages of the fractions. AP of normal starches had a polymodal CL distribution with A chains ( $\mathrm{DP}<16)$, B1 chains $(16<\mathrm{DP}<25)$, $\mathrm{B} 2$ and $\mathrm{B} 3$ chains $(25<\mathrm{DP}<80$ ), and B4 chains (DP $>80)$ (Hizukuri, 1986). Extremely long B chains of AP were described in literature (Bertoft, 2004). The longer chains of AM have a DP $>150$.

The amounts of chains that span only 1 cluster (A and B1 chains) were comparable for wtps (81.1-89.4 mol\%) and amfps (84.8-88.2 mol\%) and were slightly higher for the cassava starches (89.2-90.5 mol\%). The lamellar periodicity, i.e. $9 \mathrm{~nm}$, corresponds to the size of one cluster (Jenkins et al., 1993): double helices of 25 glucose residues, the maximum $\mathrm{CL}$ of chains that span only one cluster, had a length of $8.8 \mathrm{~nm}$. The other chains (B2, B3 and B4) span 2, 3 or 4 clusters. amfps had decreased or unchanged levels of chains with DP $<12$ when compared to wtps of the same genotype. These short chains interfered with the perfect packing of double helices.

Extremely long B chains of AP were observed for all amfps $( \pm 1000$ glucose units). These results are in agreement with observations for starches of different botanical sources (Bertoft, 2004). amfps1-4 had higher levels of long B chains with DP 25150 (11.3-14.0 mol\%) than wtps (9.5-11.8 mol\%). haps had higher levels of long chains with DP > 150 (3.4-28.6 mol\%) than wtps. Comparison of AM contents (Table 2; 27.4-37.3 weight\%) and levels of chains of DP $>150$ (52.5-67.3 weight\%) of haps1-3 indicated that these long chains did not only originate from AM. Probably, the polymodal CL distribution is slightly different. The suppression of SBE A and SBE B in haps samples is probably responsible for a decreased level of $\alpha-(1,6)$ bonds which is in line with the increased AP CL. As observed earlier, cassava starches had shorter chains than potato starches.

WAXD measurements revealed B-type diffraction patterns for all potato starches while the cassava starches displayed an A-type pattern. Literature data revealed that cassava starches have an A- or C-type pattern (Hoover, 2001). RCs of potato and cassava starches were calculated using highly crystalline B- and A-type standards, respectively (Table 2 ). The $\mathrm{RC}$ of the different wtps ranged from $30.0 \%$ to $36.0 \%$, in line with Zobel (1988). amfps showed the highest RC (34.0-38.5\%), while haps had the lowest RC (21.0-29.0\%). RCs of cassava starches were slightly higher (wtcs: $40.0 \%$ and amfcs: $49.0 \%$ ) which was also observed by Zobel (1988). amfcs had also a higher RC than wtcs.

\subsection{Relation between molecular structure aspects}

In our dataset, no linear relation was observed between the degree of phosphorylation and other structural parameters. RC was negatively correlated with AM content $\left(n=14, R^{2}=0.79, P<0.05\right)$. It is generally accepted that starch crystallinity can be ascribed to AP structural elements (French, 1984). Levels of chains with DP 6-9 led to lower RC ( $\left.n=10, R^{2}=0.51, P<0.05\right)$ while chains with DP $18-25\left(n=10, R^{2}=0.50, P<0.05\right)$ increased RC. Chains with DP 6-9 are too short to build double helices and disturb the order (Vandeputte, Vermeylen, et al., 2003b). The pitch height (6 glucose molecules/turn) of the double helices is about $2.1 \mathrm{~nm}$ (Buléon et al., 1998). Double helices formed by chains with DP 18-25 (6.3-8.8 nm) fit well in the lamellae of AP, explaining their contribution to RC. The cassava starches had shorter chains than potato starches in general. This is typically observed when comparing A-type and Btype starches (Vermeylen, Goderis, Reynaers, \& Delcour, 2004).

\subsection{Gelatinisation characteristics}

Fig. 5 presents a schematic overview of the starch gelatinisation temperatures. $T_{\mathrm{p}}$ of wtps ranged from 61.7 to $65.7^{\circ} \mathrm{C}$. It was higher for amfps $\left(67.1-70.1^{\circ} \mathrm{C}\right)$ and highest for haps $\left(73.2-98.9^{\circ} \mathrm{C}\right)$. In line with observations for potato starches, amfcs had higher $T_{\mathrm{p}}\left(63.6^{\circ} \mathrm{C}\right)$ than wtcs $\left(60.7^{\circ} \mathrm{C}\right)$. Their gelatinisation temperatures were lower than those of potato starches. Gelatinisation temperature ranges $\left(T_{\mathrm{C}}-\mathrm{T}_{\mathrm{O}}\right)$ of amfps $\left(7.9-11.1{ }^{\circ} \mathrm{C}\right)$ and amfcs $\left(14.8^{\circ} \mathrm{C}\right)$ were smaller than or similar to those of wtps $\left(8.4-11.2^{\circ} \mathrm{C}\right)$ and wtcs $\left(15.3^{\circ} \mathrm{C}\right)$, respectively. In addition, haps had a broad gelatinisation temperature range $\left(25.0-46.7{ }^{\circ} \mathrm{C}\right)$ presumably due to a heterogeneous starch population. $\Delta H$ was respectively higher and lower for amfps (23.1-25.9 J/g) and haps (6.1-19.2 J/g) than for their parent starch. Cassava starches (A-type starch) had lower enthalpies (19.5-21.5 J/ g) than potato starches (B-type starch). This was already earlier observed by Fredriksson et al. (1998) for A- (wheat, rye and barley starches) and B-type starches (potato starch).

\subsection{Structure related to gelatinisation characteristics}

No linear correlation was observed between the gelatinisation temperatures and $\mathrm{RC}$ or $\mathrm{AM}$ content. In contrast, parameters describing CL distributions correlated with gelatinisation temperature. Levels of short chains, i.e. DP 6-9 $(n=15$ with haps 4 excluded, $R^{2}=0.66,0.77$ and $\left.0.63, P<0.05\right)$ and DP $10-14\left(n=16, R^{2}=0.66\right.$, 0.88 and $0.91, P<0.05$ ), were negatively correlated with $T_{0}, T_{\mathrm{p}}$ and $T_{\mathrm{c}}$, respectively. Levels of chains with DP $18-25\left(n=16, R^{2}=0.64,0.80\right.$ and 0.76, $P<0.05$ ) were positively correlated with $T_{0}, T_{\mathrm{p}}$ and $T_{\mathrm{c}}$, respectively. Also, levels of chains with $\mathrm{DP}>25\left(n=16, R^{2}=0.91\right.$ and $0.95, P<0.05)$ were positively correlated with $T_{\mathrm{p}}$ and $T_{\mathrm{c}}$, respectively. The Pearson correlation coefficients $(R)$ for the relation between the relative levels of chains of each DP and $T_{0}, T_{\mathrm{p}}$ and $T_{\mathrm{c}}$ were plotted as a function of DP (Fig. 6). Gelatinisation was delayed with higher relative amounts of DP 18-30 and lower relative proportions of DP 8-14 chains. These observations are in line with results for waxy and normal rice starches (Vandeputte, Vermeylen, et al., 2003b). However, we observed an increase of the gelatinisation temperatures at slightly higher DP (DP 18-25 instead of DP 12-22). Again, this can be explained by the longer chains of B-type starches (potato) than A-type starches (cassava) (Vermeylen et al., 2004).

Levels of longer chains with DP 25-80 ( $n=16, R^{2}=0.65,0.96$ and $0.79, P<0.05)$ and with DP $80-150\left(n=16, R^{2}=0.65,0.87\right.$ and $0.71, P<0.05$ ), measured by HPSEC, were positively correlated with $T_{0}, T_{\mathrm{p}}$ and $T_{\mathrm{c}}$, respectively. These chains are suggested to contribute to more stable crystals and hence delayed gelatinisation. Especially $T_{\mathrm{p}}$ showed strong correlations with CL distribution. 
A positive relation was observed between $\Delta H$ and RC ( $n=14$, $\left.R^{2}=0.81, P<0.05\right)$, indicating that the gelatinisation enthalpy increased with crystallinity. Although RC is suggested in literature to be affected by CL distribution, no relation was found between $\Delta H$ and CL distribution. In line with Karlsson and Eliasson (2003), no influence of granule size on gelatinisation behaviour was observed.

\section{Conclusions}

The granules of potato starches are large and oval to spherical (10-110 $\mu \mathrm{m})$ and those of cassava starches small and oval to round with a small population having a truncated end. Potato starches have a B-type diffraction pattern and a limited degree of phosphorylation whereas cassava starches show an A-type diffraction pattern and contain little if any phosphate ester groups. AM content, RC and AP CL distribution affect the gelatinisation behaviour of potato and cassava starches. AP CLs of the potato starches are longer than those of cassava starches. This results in lower gelatinisation temperatures for the cassava starches. Short chains (DP $<14$ ) prevent crystalline order, whereas longer chains (DP $>18$ ) yield more stable crystals. Consequently, increased levels of longer chains shift gelatinisation to higher temperatures, whereas short chains decrease the gelatinisation temperatures. Increased crystallinity and consequently increased AM content results in higher $\Delta H$-values. No relation was observed between the granular structure and the gelatinisation properties.

\section{Acknowledgements}

We thank Evy Van Calster, Luc Suurs, Alexander Vrijdaghs and Luc Van Den Ende for technical assistance. The 'Instituut voor aanmoediging van Innovatie door Wetenschap en Technologie in Vlaanderen' (IWT, Brussels, Belgium) is thanked for financial support. This study was in part carried out within the framework of research projects GOA/03/10 financed by the Research Fund K.U. Leuven. It is also part of the Methusalem programme "Food for the Future" at the K.U. Leuven.

\section{References}

Association of Official Analytical Chemists. (1995). Method 990.03. InOfficial methods of analysis, Vol 16. Washington, DC: Association of Official Analytical Chemists.

Bay-Smidt, A. M., Blennow, A., Bojko, M., \& Moller, B. L. (1999). The effect of phosphate and amylopectin molecular size on peak viscosity of starch pastes. Annual Transactions of the Nordic Rheology Society 731-738.

Bay-Smidt, A. M., Wischmann, B., Olsen, C. E., \& Nielsen, T. H. (1994). Starch bound phosphate in potato as studied by a simple method for determination of organic phosphate and P-31-NMR. Starch - Stärke, 46(5), 167-172.

Bertoft, E. (2004). Analysing starch structure. In A. C. Eliasson (Ed.), Starch in food: structure, function and applications (pp. 57-96)

Blennow, A., Bay-Smidt, A. M., \& Bauer, R. (2001). Amylopectin aggregation as a function of starch phosphate content studied by size exclusion chromatography and on-line refractive index and light scattering. International Journal of Biological Macromolecules, 28(5), 409-420.

Blennow, A., Wischmann, B., Houborg, K., Ahmt, T., Jorgensen, K., Engelsen, S. B., et al. (2005). Structure function relationships of transgenic starches with engineered phosphate substitution and starch branching. International Journal of Biological Macromolecules, 36(3), 159-168.

Buléon, A., Colonna, P., Planchot, V., \& Ball, S. (1998). Starch granules: structure and biosynthesis. International Journal of Biological Macromolecules, 23(2), 85-112.

Daniels, D. R., \& Donald, A. M. (2003). An improved model for analyzing the small angle X-ray scattering of starch granules. Biopolymers, 69(2), 165-175.

Donald, A. M., Kato, K. L., Perry, P. A., \& Weigh, T. A. (2001). Scattering studies of the internal structure of starch granules. Starch - Stärke, 53(10), 504-512.

Dubois, M., Gilles, K. A., Hamilton, J. K., Rebers, P. A., \& Smith, F. (1956). Colorimetric method for determination of sugars and related substances. Analytical Chemistry 28350-28356.

Fredriksson, H., Silverio, J., Andersson, R., Eliasson, A. C., \& Aman, P. (1998). The influence of amylose and amylopectin characteristics on gelatinization and retrogradation properties of different starches. Carbohydrate Polymers, 35(3-4), 119-134.
French, D. (1984). Organization of starch granules. In R. L. Whistler, J. N. Bemiller, \& E. F. Paschal (Eds.), Starch chemistry and technology (pp. 183-212). New York: Academic Press.

Fulton, D. C., Edwards, A., Pilling, E., Robinson, H. L., Fahy, B., Seale, R., et al. (2002). Role of granule-bound starch synthase in determination of amylopectin structure and starch granule morphology in potato. Journal of Biological Chemistry, 277(13), 10834-10841.

Gallant, D. J., Bouchet, B., \& Baldwin, P. M. (1997). Microscopy of starch: evidence of a new level of granule organization. Carbohydrate Polymers, 32(3-4), 177-191.

Gerard, C., Barron, C., Colonna, P., \& Planchot, V. (2001). Amylose determination in genetically modified starches. Carbohydrate Polymers, 44(1), 19-27.

Hizukuri, S. (1986). Polymodal distribution of the chain lengths of amylopectins, and its significance. Carbohydrate Research, 147(2), 342-347.

Hizukuri, S. (1996). Starch: analytical aspects. In A. C. Eliasson (Ed.), Carbohydrates in food (pp. 347-429). New York: Marcel Dekker.

Hoover, R. (2001). Composition, molecular structure, and physicochemical properties of tuber and root starches: a review. Carbohydrate Polymers, 45(3), 253-267.

Hovenkamp-Hermelink, J. H. M., Jacobsen, E., Ponstein, A. S., Visser, R. G. F. Vosscheperkeuter, G. H., Bijmolt, E. W., et al. (1987). Isolation of an amylose-free starch mutant of the potato (Solanum tuberosum L.). Theoretical and Applied Genetics, 75(1), 217-221.

Jacobs, H., Eerlingen, R. C., Rouseu, N., Colonna, P., \& Delcour, J. A. (1998). Acid hydrolysis of native and annealed wheat, potato and pea starches - DSC melting features and chain length distributions of lintnerised starches. Carbohydrate Research, 308(3-4), 359-371.

Jenkins, J. P. J., Cameron, R. E., \& Donald, A. M. (1993). A universal feature in the structure of starch granules from different botanical sources. Starch - Stärke, 45(12), 417-420.

Jenkins, P. J., \& Donald, A. M. (1995). The influence of amylose on starch granule structure. International Journal of Biological Macromolecules, 17(6), 315-321.

Jobling, S. (2004). Improving starch for food and industrial applications. Current Opinion in Plant Biology, 7(2), 210-218.

Karlsson, M. E., \& Eliasson, A. C. (2003). Gelatinization and retrogradation of potato (Solanum tuberosum) starch in situ as assessed by differential scanning calorimetry (DSC). Lebensmittel-Wissenschaft Und-Technologie - Food Science and Technology, 36(8), 735-741.

Klucinec, J. D., \& Thompson, D. B. (1998). Fractionation of high-amylose maize starches by differential alcohol precipitation and chromatography of the fractions. Cereal Chemistry, 75(6), 887-896.

Koch, K., Andersson, R., \& Aman, P. (1998). Quantitative analysis of amylopectin unit chains by means of high-performance anion-exchange chromatography with pulsed amperometric detection. Journal of Chromatography A, 800(2) 199-206.

Kuipers, A. G. J., Jacobsen, E., \& Visser, R. G. F. (1994). Formation and deposition of amylose in the potato-tuber starch granule are affected by the reduction of granule-bound starch synthase gene-expression. Plant Cell, 6(1), 43-52.

Mikkelsen, R., Baunsgaard, L., \& Blennow, A. (2004). Functional characterization of alpha-glucan, water dikinase, the starch phosphorylating enzyme. Biochemical Journal, 377(2), 525-532.

Moorthy, S. N. (2002). Physicochemical and functional properties of tropical tuber starches: a review. Starch - Stärke, 54(12), 559-592.

Morrison, W. R., \& Karkalas, J. (1990). Starch. In P. M. Dey, \& J. B. Harborne (Eds.), Methods in plant biochemistry (pp. 323-352). New York, USA: Academic Press.

Oostergetel, G. T., \& van Bruggen, E. F. J. (1989). On the origin of a low-angle spacing in starch. Starch - Stärke, 41(9), 331-335.

Raemakers, K., Schreuder, M., Suurs, L., Furrer-Verhorst, H., Vincken, J. P., de Vetten, N., et al. (2005). Improved cassava starch by antisense inhibition of granule-bound starch synthase I. Molecular Breeding, 16(2), 163-172.

Schwall, G. P., Safford, R., Westcott, R. J., Jeffcoat, R., Tayal, A., Shi, Y. C., et al. (2000) Production of very-high-amylose potato starch by inhibition of SBE A and B. Nature Biotechnology, 18(5), 551-554.

Shi, Y. C., Capitani, T., Trzasko, P., \& Jeffcoat, R. (1998). Molecular structure of a lowamylopectin starch and other high-amylose maize starches. Journal of Cereal Science, 27(3), 289-299.

Tabata, S., \& Hizukuri, S. (1971). Studies on starch phosphate. Part 2. Isolation of glucose 3-phosphate and maltose phosphate by acid hydrolysis of potato starch. Starch - Stärke, 23(8), 267-272.

Takeda, Y., \& Hizukuri, S. (1982). Location of phosphate groups in potato amylopectin. Carbohydrate Research, 102(1), 321-327.

Umemoto, T., Nakamura, Y., Satoh, H., \& Terashima, K. (1999). Differences in amylopectin structure between two rice varieties in relation to the effects of temperature during grain-filling. Starch - Stärke, 51(2-3), 58-62.

Vandeputte, G. E., Derycke, V., Geeroms, J., \& Delcour, J. A. (2003). Rice starches. II. Structural aspects provide insight into swelling and pasting properties. Journal of Cereal Science, 38(1), 53-59.

Vandeputte, G. E., Vermeylen, R., Geeroms, J., \& Delcour, J. A. (2003a). Rice starches. III. Structural aspects provide insight in amylopectin retrogradation properties and gel texture. Journal of Cereal Science, 38(1), 61-68.

Vandeputte, G. E., Vermeylen, R., Geeroms, J., \& Delcour, J. A. (2003b). Rice starches. I. Structural aspects provide insight into crystallinity characteristics and gelatinisation behaviour of granular starch. Journal of Cereal Science, 38(1), 43-52.

Vermeylen, R., Goderis, B., Reynaers, H., \& Delcour, J. A. (2004). Amylopectin molecular structure reflected in macromolecular organization of granular starch. Biomacromolecules, 5(5), 1775-1786. 
Visser, R. G. F., Somhorst, I., Kuipers, G. J., Ruys, N. J., Feenstra, W. J., \& Jacobsen, E. (1991). Inhibition of the expression of the gene for granule-bound starch synthase in potato by antisense constructs. Molecular E General Genetics, 225(2), 289-296.

Visser, R. G. F., Suurs, L. C. J. M., Bruinenberg, P. M., Bleeker, I., \& Jacobsen, E. (1997) Comparison between amylose-free and amylose containing potato starches. Starch - Stärke, 49(11), 438-443.

Waffenschmidt, S., \& Jaenicke, L. (1987). Assay of reducing sugars in the nanomole range with 2,2'-bicinchoninate. Analytical Biochemistry, 165(2), 337-340.

Waigh, T. A., Kato, K. L., Donald, A. M., Gidley, M. J., Clarke, C. J., \& Riekel, C. (2000). Side-chain liquid-crystalline model for starch. Starch - Stärke, 52(12), 450-460
Wakelin, J. H., Virgin, H. S., \& Crystal, E. (1959). Development and comparison of two $\mathrm{X}$-ray methods for determining the crystallinity of cotton cellulose. Journal of Applied Physics, 30(11), 1654-1662.

Yoo, S. H., \& Jane, J. L. (2002). Molecular weights and gyration radii of amylopectins determined by high-performance size-exclusion chromatography equipped with multi-angle laser-light scattering and refractive index detectors. Carbohydrate Polymers, 49(3), 307-314.

Yun, S. H., \& Matheson, N. K. (1990). Estimation of amylose content of starches after precipitation of amylopectin by concanavalin-A. Starch - Stärke, 42(8), 302-305.

Zobel, H. F. (1988). Molecules to granules - a comprehensive starch review. Starch Stärke, 40(2), 44-50. 